\title{
EXPERIMENTANDO ATITUDES E SENTIMENTOS: O COTIDIANO HEMODIALÍTICO COMO BASE PARA O CUIDAR EM ENFERMAGEM
}

\author{
Experimenting attitudes and feelings: the everyday of the \\ hemodialysis as basis of nursing care \\ Probando actitudes y sentimientos: el cotidiano de \\ la hemodiálisis como base para el cuidar en enfermería
}

Glaucia Valente Valadares ${ }^{2}$

\section{RESUMO}

0 presente estudo tem como objetivo: discutir a relação do enfrentamento do cliente dependente de hemodiálise em termos de possibilidades para o cuidado de enfermagem. Adotaram-se como referenciais teóricos a visão sistêmica do indivíduo e conceitos de enfrentamento. A trajetória metodológica percorrida foi a da pesquisa qualitativa, utilizando os princípios básicos da Teoria Fundamentada nos Dados (TFD). 0 cenário do estudo foi uma Associação de Renais e Transplantados do Estado do Rio de Janeiro. Os participantes da pesquisa foram indivíduos dependentes de hemodiálise ligados a esta associação. Para resgate dos dados, foram adotadas a observação participante sistemática e a entrevista semiestruturada em profundidade. As informações foram analisadas considerando-se os procedimentos básicos pertinentes a TFD: codificação aberta, codificação axial e codificação seletiva. Entre muitos aspectos, o estudo aponta para a relação de interdependência entre conhecimento e sensibilidade para garantir que o cuidado prestado esteja embasado na visão sistêmica do indivíduo.

Palavras-chave: Assistência Centrada no Paciente. Diálise Renal. Cuidados de Enfermagem

\begin{abstract}
This study aims to: discuss the relation of the patient's confrontation on hemodialysis in terms of possibilities for nursing care. Adopted as a theoretical reference the vision of the individual and systemic concepts of confrontation. The path traveled was the methodology of qualitative research, using the basic principles of Grounded Theory. The scenario of the study was an association of kidney and transplanted from Rio de Janeiro State. The participants of the research subjects were dependent on dialysis involved in this association. To rescue the data were taken by participant observation and semi-structured in depth. The information was analyzed, considering the basic procedures relevant to Grounded Theory: open coding, coding axial and coding selective. Among many things, the study points to the relationship of interdependence of knowledge and sensitivity to ensure that the care provided is based on the systemic view of the individual.
\end{abstract}

Keywords: Patient-centered care. Renal Dialysis. Nursing care.

\section{Resumen}

El presente estudio tiene como objetivo: discutir la relación del enfrentamiento de los clientes dependientes de la hemodiálisis en términos de posibilidades para el cuidado de enfermería. Se aprobó como referencial teórico de la visión sistémica de la persona y los conceptos de la confrontación. La trayectoria metodológica fue de la investigación cualitativa, utilizando los principios básicos de la Teoría Fundamentada en los Datos (TFD). La escena del estudio fue una asociación de enfermos de riñón y trasplantados del Estado de Río de Janeiro. Los participantes de la investigación han sido en personas dependientes de hemodiálisis a esta asociación. Para el resgate de los datos fue adoptado la observación participante sistemática y la entrevista de media estructuralizarse en profundidad. La información se ha analizado, teniendo en cuenta los procedimientos básicos pertinentes de la TFD: la codificación abierta, axial y selectiva de la codificación. Entre muchos aspectos, el estudio señala la relación de interdependencia entre los conocimientos y la sensibilidad para garantía de que la atención dada se basa en la visión sistémica de la persona.

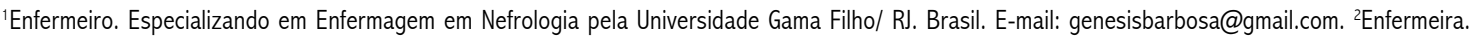
${ }^{2}$ Doutora em Enfermagem. Docente chefe do Departamento de Enfermagem Fundamental da Escola de Enfermagem Anna Nery da Universidade Federal do Rio de Janeiro. Orientadora. Brasil. E-mail: glauciavaladares@ig.com.br
} 


\section{INTRODUCÃO}

Trata este estudo de um recorte do Trabalho de Conclusão de Curso intitulado: "A construção do conhecimento em saúde a partir do enfrentamento do cliente dependente de hemodiálise: o desafio cotidiano". Assim, procurou-se compreender o modo como os clientes dependentes de hemodiálise vivenciam o processo de enfrentamento.

Para iniciar a problemática, cabe ressaltar que vivemos em mundo globalizado onde se torna imperativo que o trabalhador seja dotado de amplo conhecimento teórico e prático, com aprofundamento específico no que tange a uma dada área de atuação e ao processo de trabalho, sem a perda da totalidade'.

A tendência à especialização reforça a inclinação pelo tratamento de partes específicas do corpo, perdendo-se assim a visão do indivíduo como um todo. Essa vocação ocorre porque estamos culturalmente condicionados a pensar de forma reducionista, modelo que foi consolidado por René Descartes ao dividir o todo e estudá-lo em partes separadas².

Alguns tratamentos provêm, essencialmente, de uma abordagem reducionista, altamente mecanizada, especializada e impessoal, de um modelo exíguo para explicar enfoques mais abrangentes, como a saúde da população. Essas descobertas representam papel decisivo no avanço da assistência ao ser humano; no entanto, se faz necessário, transcender o modelo biomédico cartesiano e discutir a redefinição da aplicação tecnológica na questão da saúde, sob o prisma da enfermagem como prática assistencial humanizada integral à saúde ${ }^{3}$.

Assim sendo, torna-se imperativo que conceitos como o de saúde e doença sejam delineados e compreendidos. 0 conceito de saúde deve, portanto, possuir uma visão sistêmica do indivíduo. A Constituição da Organização Mundial da Saúde (OMS), de 1946, define saúde como um estado de completo bem-estar físico, mental e social, e não meramente a ausência de doenças ou enfermidades ${ }^{4}$.

Esta definição trata a saúde de forma estática, constituindo, portanto, algo irreal uma vez que enxergamos a saúde como um fenômeno multidimensional que envolve aspectos físicos, psicológicos e sociais, que são interdependentes. Apesar de ilusória, esta definição revela a importância de focalizar 0 indivíduo com abordagem holística enxergando-o como um ser total.

Cabe salientar que a OMS propôs a emenda de sua Constituição em 1998, solicitando que fosse considerada a definição de saúde como o estado dinâmico de completo bemestar físico, mental, espiritual e social ${ }^{5}$. A adoção desta nova conceituação reforça a importância de direcionar a assistência ao indivíduo de modo sistêmico, não se detendo a assistir apenas à doença em questão.
0 modelo biomédico cartesiano tem como princípios básicos enraizados em nossa cultura o modelo de doença, em que doenças são entidades bem definidas que envolvem mudanças estruturais em bases celulares e têm raízes causais únicas².

Considerando que o ser humano não é somente a esfera física, nem somente consciência ou apenas emoções, avaliar alguns destes aspectos isoladamente é perder de vista a totalidade e a integridade, que deve ser foco permanente dos profissionais que lidam com a saúde, uma vez que fatores que não estão diretamente ligados à doença podem interferir em seu estado de equilíbrio ${ }^{6}$.

Assim, este estudo aborda a doença enquanto processo, pois apresenta uma perspectiva mais compreensiva que incorpora os indivíduos e suas famílias, na medida em que tomam contato, se adaptam respondendo aos sintomas e deficiências e, como não poderia deixar de ser, utilizam estratégias para enfrentar o processo de modo que seja possível desempenhar suas funções junto à sociedade.

A experiência da doença enquanto processo visa integrar corpo e mente e inseri-los num contexto sociocultural, além de uma entidade fisiológica ${ }^{6}$. Deste modo, a necessidade do profissional de se sensibilizar para captar as necessidades e dificuldades da clientela assistida e, então, flexibilizar todos os tipos de conhecimento diante da realidade vivenciada constitui um predicado que deve estar conexo à aplicação de técnicas e conhecimentos específicos. Percebemos então a relação de interdependência de conhecimento e sensibilidade para garantir que o cuidado prestado esteja embasado na visão sistêmica do indivíduo.

A idéia de abordar doença como um processo contínuo revela a necessidade de atentar para a visão sistêmica do indivíduo contrapondo o modelo biomédico atual, desta forma, passando a não mais focar as unidades menores somente e, sim, o todo da matéria, da vida e da mente que se influenciam e se determinam reciprocamente. Portanto, quando a atenção atende a estes aspectos tem-se a concepção holística da saúde.

Considerando as idéias até aqui apresentadas, o objetivo deste estudo foi: discutir a relação do enfrentamento do cliente dependente de hemodiálise em termos de possibilidades para o cuidado de enfermagem. A este ponto, como não poderia deixar de ser mencionado, este cliente é um indivíduo que vivencia uma brusca mudança no seu cotidiano, com repercussões complexas em sua vida.

De tal modo, os profissionais devem considerar, em que pese o cuidado de enfermagem, que cada pessoa possui uma forma peculiar para o enfrentamento de situações diversas, que podem ser, inclusive, bastante estressoras. 0 modo como a pessoa desenvolve as habilidades cognitivas para 0 enfrentamento é um processo mental individual, e cada um tem diferentes níveis de capacidade para enfrentar ou responder aos estressores 8 . 


\section{TRAJETÓRIA TEÓRICO-METODOLÓGICA}

Para contextualizar a situação de saúde vivenciada pelos sujeitos da pesquisa, foram apresentados conceitos à luz da visão sistêmica que entende a saúde como um fenômeno multidimensional, que envolve aspectos da esfera física, psicológica e social que são, por sua vez, interdependentes.

Nesse sentido, a "condição crônica de saúde" envolve estudos que dizem respeito aos aspectos psicológicos, sociológicos, econômicos, culturais e afetivos, que, pela diversidade e abrangência, instigam a necessidade de ampliar discussões diante da complexidade envolvida ${ }^{9}$.

No que se refere à conceituação de doença crônica, o termo mais divulgado e reconhecido a descreve como todos os obstáculos ou desvios do normal, os quais apresentem uma ou mais das seguintes características: são permanentes, deixando incapacidade residual; são causados por alteração patológica irreversível, demandando treinamento especial do cliente para sua reabilitação, além de longo período de gerenciamento, observação e cuidado e, potencialmente, alterando a autonomia do indivíduo ${ }^{10}$.

Ampliando o conceito, temos a doença crônica como uma intercorrência estressora, com um impacto que pode surgir a qualquer tempo e permanecer, alterando o processo saudável de indivíduos ou de grupos. Este impacto determina um rumo ao processo de viver e estar em equilíbrio de acordo com o significado que é atribuído a estes estressores, com a orientação de vida, com as forças, necessidades e estratégias de enfrentamento utilizadas pelos envolvidos ${ }^{11}$.

Para ser saudável, um organismo necessita estar em equilibrio e preservar sua autonomia individual ${ }^{2}$. A mudança do modo de vida acarretada pela doença crônica afeta estes indivíduos que se deparam com a situação de dependência ocasionada pela rotina empregada no tratamento, o que afeta, além de sua vida cotidiana, seu estado de equilíbrio.

Além das interferências no processo de equilíbrio e na vida cotidiana dos clientes dependentes de hemodiálise e da rotina imposta pela natureza do tratamento, existe a situação de dependência que configura risco ao princípio da autonomia, que deve ser preservado também em seus aspectos bioéticos na assistência a essa clientela. Em especial, porque a autonomia é um princípio que contempla a idéia de que o cliente deve ter uma participação ativa no processo de tomada de decisão, e que sua vontade deve ser respeitada, estando ele bem informado e plenamente capaz do ponto de vista psicológico ${ }^{12}$.

Quando a autonomia é perdida ou afetada, o cliente sofre alteração no seu equilibrio, alterando o processo saúde-doença. Cabe à equipe que presta assistência ao cliente que sofre com a perda da autonomia, que antes a detinha por completo, estabelecer mecanismos que o auxiliem na promoção de sua saúde, discutida aqui de modo dinâmico.

Desta forma, entendemos que se faz necessário apontar uma definição de saúde que faça a abordagem da mesma de modo sistêmico, uma vez que apontar a representação comum de saúde e doença como extremos opostos de algo contínuo e unidimensional é uma idéia enganadora, pois a doença física pode ser contrabalançada por uma atitude mental positiva e por apoio social, de modo que o estado global seja de bemestar?

Na busca por uma assistência enraizada na visão sistêmica, precisamos concentrar nossa atenção na identificação das forças do indivíduo que porta a doença com a mesma atenção cuidadosa que nos dedicamos à identificação do próprio processo de adoecer, pois podem existir partes num indivíduo que vivencia a doença que continuam com recursos que podem se desenvolver a partir da uma situação de crise. Quando está presente e é reconhecida, a força destas partes pode ser despertada para lidar com o problema e colaborar no restabelecimento do bem-estar, provocando melhoria na qualidade de vida deste indivíduo ${ }^{6}$.

0 termo "qualidade de vida" foi utilizado pela primeira vez pelo presidente dos EUA, em 1964, e ainda hoje percebemos que há grande preocupação, em nível mundial, no que tange à definição da qualidade de vida e suas relações ${ }^{13}$. Trata-se de um conceito subjetivo que envolve todos os componentes essenciais à condição humana, sejam eles do campo físico, psicológico, cultural ou espiritual ${ }^{14}$.

0 significado de qualidade de vida está ligado à subjetividade das pessoas que associam a este conceito uma dimensão mais ampla, de modo a satisfazer as necessidades básicas e aspirações pessoais apropriando-se de mecanismos de enfrentamento e adaptação às possíveis limitações a eles apresentadas ${ }^{15}$.

A doença renal tem impacto negativo sobre a qualidade de vida, no que diz respeito às limitações do cotidiano destes indivíduos e as mudanças que interferem no cotidiano como: perda de emprego, alterações na imagem corporal, restrições dietéticas e hídricas. Cabe destacar, ainda, que esses parâmetros têm sido utilizados para analisar o impacto das doenças crônicas no cotidiano e, para isso, é necessário avaliar indicadores de funcionamento físico, aspectos sociais, estado emocional e mental, da repercussão de sintomas e da percepção individual de bem-estar ${ }^{16}$.

Ao vivenciar a condição crônica de saúde, o cliente dependente de hemodiálise experimenta, no momento em que Ihe é informada a situação de dependência do tratamento dialítico, uma série de sentimentos e sensações, que partem de conceitos previamente concebidos acerca do contexto ao qual agora está inserido, além da capacidade de lidar com situações estressoras e o significado atribuído a estes estressores. Estes fatores determinam os mecanismos de enfrentamento que ele utilizará no processo".

0 enfrentamento exige significativa capacidade de comunicação, fundamentalmente, uma importante capacidade interativa. Sem abertura para a interação o indivíduo, torna-se cada vez mais propenso ao entendimento apenas dos seus 
próprios valores, limitando o seu crescimento a partir da crise vivenciada pela situação de saúde, tendo uma atitude fechada, com dificuldades de ser flexível nas situações estressoras apresentadas pelo cotidiano, comprometendo o processo de crescimento'.

A vivência e a superação de obstáculos são estímulos à atividade cognitiva, na qual o desafio cognitivo faz o indivíduo se mobilizar'. Partindo dessa premissa, é importante para os clientes dependentes de hemodiálise que os enfermeiros adotem estratégias de encorajamento para o enfrentamento de situações estressoras por eles vivenciadas.

Para compreensão do fenômeno investigado, a fim de entender como ocorre o enfrentamento do cliente dependente de hemodiálise, a abordagem da Teoria Fundamentada nos Dados (TFD) mostrou-se significativamente apropriada. A TFD é um método sistemático de pesquisa qualitativa que tem como finalidade construir uma teoria, com base nos dados investigados, para elucidar um determinado fenômeno presente na realidade ${ }^{17}$.

Este estudo traz como referencial metodológico princípios básicos da TFD que buscam entender, através de uma análise profunda, os processos a partir dos quais acontece o fenômeno investigado. Para o momento acadêmico no qual este estudo se inseriu, optou-se por seguir os princípios básicos da TFD que pudessem permitir o resgate do fenômeno. Então, foram adotadas a distribuição vertical do discurso, codificação aberta, codificação axial e codificação seletiva para delineamento do fenômeno apresentado.

A TFD fornece explicações de como os eventos ocorrem e, desse modo, pode ajudar os enfermeiros a explorarem os dados com maior riqueza e em contextos relativamente desconhecidos, permitindo o entendimento interpretativo da assistência que estão realizando ${ }^{18}$.

0 cenário da pesquisa foi uma associação de renais e transplantados que tem como características principais: ser uma entidade de controle social, sem fins lucrativos, com caráter fiscalizador e informativo. Os sujeitos da pesquisa foram 10 dependentes de hemodiálise, sendo 7 mulheres e 3 homens, todos residentes na cidade do Rio de Janeiro, com tempo de tratamento hemodialítico entre 2 e 25 anos.

Na coleta dos dados, foi utilizada a observação participante e a entrevista semiestruturada como instrumentos para resgate do fenômeno. A observação participante sistemática foi adotada, pois é um recurso que possibilita a compreensão da realidade através do contato pessoal e estreito do pesquisador com o fenômeno pesquisado e, ainda, através da busca de informações acerca de questões que podem emergir deste processo que se configura como uma vantagem para a pesquisa, mesmo quando há necessidade de compreensão de elementos resultantes da coleta de dados.

No que concerne à entrevista, foi adotada uma proposta de interação em profundidade através de um instrumento de coleta de dados semiestruturado com margem de flexibilidade, no que diz respeito aos dados a recolher, pois os entrevistados foram encorajados a expressar as suas opiniões e sentimentos sobre 0 assunto investigado.

A seguir foi realizada a análise dos dados obtidos com base no referencial adotado, transcrevendo as gravações (distribuiç̧ão vertical do discurso), codificando as entrevistas linha a linha (codificação aberta) e logo após classificando os códigos primeiramente em subcategorias, que em seguida se integraram a grupos maiores, as categorias (codificação axial). Essas etapas serviram de base para a codificação seletiva, uma etapa posterior na qual as categorias e subcategorias possibilitaram emergir a categoria (fenômeno) central.

0 fenômeno central é a categoria que engloba todas as outras após o processo analítico no qual as categorias são analisadas profundamente. 0 fenômeno as mantém unidas tornando possível, neste estudo, explicitar a vivência experienciada pelos clientes dependentes de hemodiálise no que concerne ao modo de enfrentamento.

Foram respeitados os princípios éticos na pesquisa, delineados na Resolução 196/96, que versa sobre pesquisas envolvendo os seres humanos ${ }^{19} .0$ projeto desta pesquisa foi aprovado pelo Comitê de Ética em Pesquisa da Escola de Enfermagem Anna Nery/Hospital Escola São Francisco de Assis (Protocolo $N^{0}$. 056/07). Os participantes tomaram conhecimento e assinaram o Termo de Consentimento Livre e Esclarecido (TCLE), concordando assim em participar deste estudo. Cabe salientar também, que para garantir sigilo e em conformidade com o referencial adotado, foram utilizados os pseudônimos: Ametista, Citrino, Esmeralda, Ônix, Quartzo Rosa, Quartzo Fumê, Rubi, Safira, Turmalina e Cristal.

\section{DISCUSSÃO DOS RESULTADOS}

A categoria "Experimentando emoções e atitudes: a vivência acomodada ao cotidiano" se expressa a partir da associação de cinco subcategorias: "Aprendendo a buscar e experimentar atitudes e sentimentos"; "Sendo assistido: a vivência da acolhida no serviço de saúde"; "A condição de saúde desgastante: idas e vindas"; "Acompanhando o tratamento à luz da esperança" e "Percebendo o cotidiano modificado", conforme esquema diagramático a seguir. 


\section{FIGURA I - ESQUEMA DIAGRAMÁTICO}

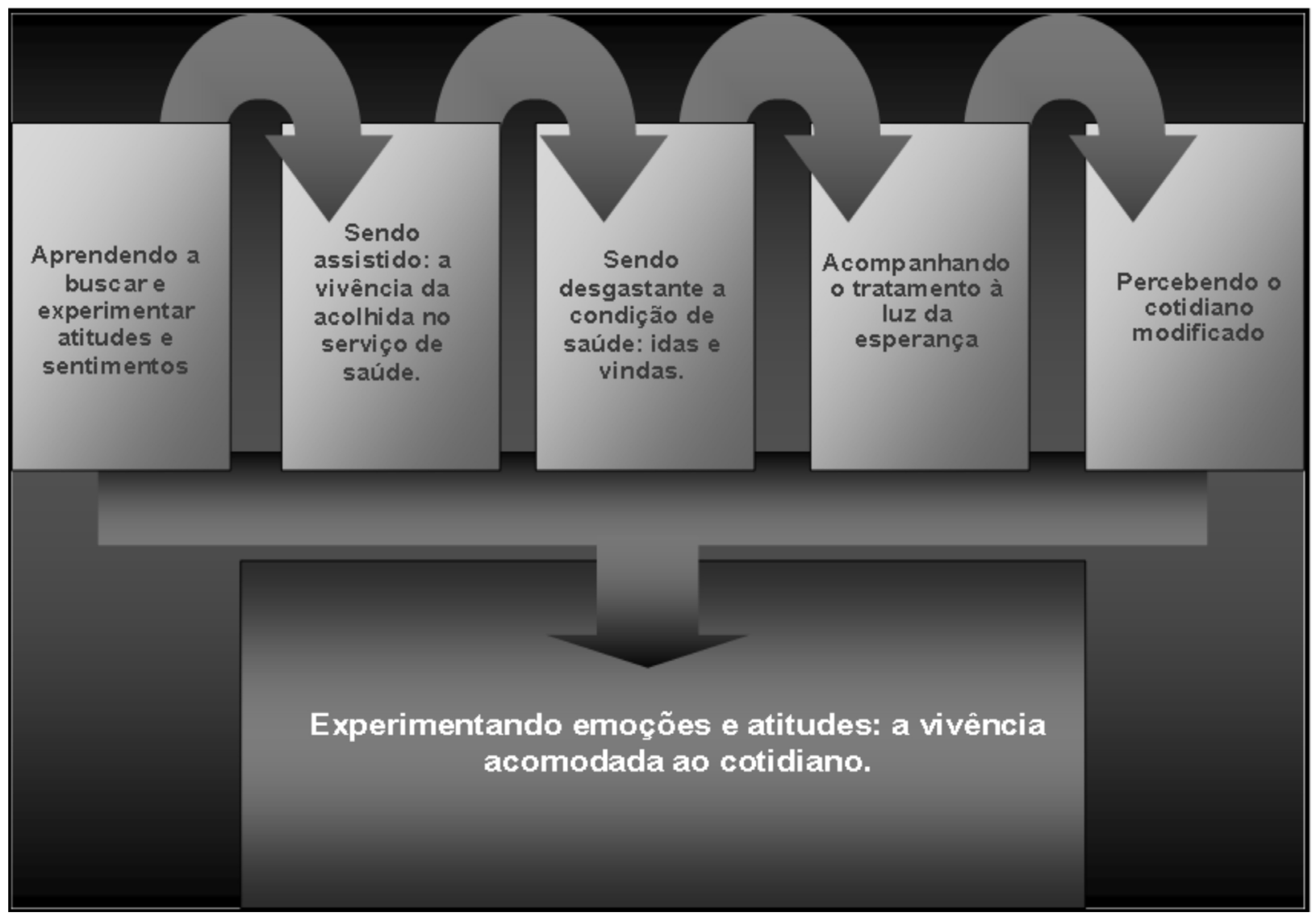

Figura 1: Categoria "Experimentando emoções e atitudes: a vivência acomodada ao cotidiano".

0 cliente dependente de hemodiálise sofre o impacto inicial no momento em que percebe as alterações provocadas pelo mau funcionamento ou insuficiência do órgão. Durante esse primeiro contato, ele experimenta um turbilhão de emoções advindas de percepções acerca da doença que ele detinha, ou ainda, vivencia em seu meio social as experiências que "ser doente renal" podem lhes proporcionar, quer sejam de união de esforços para manutenção do equilibrio e bem-estar, quer sejam situações estigmatizantes.

Passado o impacto da situação inicial, o indivíduo parte para uma nova etapa em seu processo de enfrentamento. Em "Aprendendo a buscar e experimentar atitudes e sentimentos", o indivíduo que já sofreu alterações na rotina e está seguindo em tratamento hemodialítico começa a buscar outras atividades sociais, seja para ocupar seu tempo e esquecer os sentimentos que antes o assolavam, seja para interagir com outros indivíduos do mesmo grupo que vivenciaram a mesma situação a fim de compartilhar a experiência e buscar aprendizado. Isso pode ser evidenciado nas falas abaixo:

Então criou aquele ciclo de amizade. Lá na minha sala, a sala onde eu dialiso, a gente se reúne, bate papo[...]. Citrino
Eles tratam a gente de igual pra igual. Ouvemnos e a gente os ouve. A gente até faz festa de amigo oculto juntos no Natal. Cristal

Eu sou muito interessada, gosto de saber das coisas, vou a palestras de tudo porque eu acho que quando a gente conhece fica tudo mais fácil, todo mundo tem medo do desconhecido não é? Ônix

Em "Sendo assistido: a vivência da acolhida no serviço de saúde", o indivíduo vivencia o atendimento no serviço reconhecendo as diferenças de atendimento por parte de grupos profissionais distintos e diferentes instituições. Ele reconhece suas necessidades e limitações e avalia o modo como é atendido nos serviços de acordo com a satisfação de suas necessidades, como expresso pelos participantes nas afirmativas a seguir:

Étudo muito difícil ou demorado. Contamos com a caridade dos outros. Cristal

As enfermeiras de lá são muito boas, boas mesmo. São muito simpáticas, se preocupam com a gente, estão sempre lá quando a gente passa mal, 
Atitudes e sentimentos: base para o cuidar Barbosa GS, Valadares GV

perguntam se estamos tomando remédio, como estamos[...]. Esmeralda

Eles percebem que não estamos bem logo que a gente chega e já vão cuidando logo pra gente melhorar o humor, dizem que a gente não pode ficar com aquela cara amarrada não, tem que rir mesmo que não tenha motivo. Safira

Esses indivíduos, apesar de experimentarem nesse momento um ajuste entre seu cotidiano, sua condição de saúde e 0 tratamento, vivem um processo dinâmico que por vezes pode deixá-los felizes pela assistência recebida, mas por outro lado pode ser desestimulante a rotina vivenciada. Fato bastante caracterizado nos trechos que se seguem e compõem a subcategoria "A condição de saúde desgastante: idas e vindas".

[...] minha única insatisfação é que o tratamento não mostra resultados aparentes nem um fim. Ônix

[...] já é muito tempo em tratamento e você não nota nenhum benefício, sabe que tem, mas não aparece nada. Cristal

A situação de saúde deste cliente, embora esteja em estado terminal, é bastante dinâmica, e as experiências, sentimentos e emoções se seguem de forma intensa durante todo 0 tratamento independente do estágio no qual o cliente esteja inserido. 0 modo como esses sentimentos se expressam podem impulsionar estes indivíduos a seguir em frente e iniciar a fase de adaptação ou trazer-lhes constantes retomadas de emoções paradoxais em que o cliente ora se sente confortado por observar outras pessoas em posição que consideram pior que as que eles vivenciam ora se sentem injustiçados ou castigados por terem de enfrentar uma condição tão devastadora.

Seguem "Acompanhando o tratamento à luz da esperança" à medida que aguardam 0 aparecimento de um doador para que seja então realizado o transplante, pois sabem que essa é a única medida que poderia modificar a situação vivida, possibilitando o fim do tratamento hemodialítico, como destacado abaixo:

\section{Eu tive que ir aceitando [...] até chegar a minha vez no transplante. Esmeralda}

Até que chegue a minha vez no transplante, tenho que ser paciente e aceitar essa condição, afinal, cura não tem, não dá pra trazer de volta o rim normal, então, só me resta esperar. Quartzo Rosa

A dependência de pessoas e equipamentos gerada pela situação crônica de saúde oferece ao tratamento um lugar muito especial na vida destes indivíduos, uma vez que toda a vida precisa ser ajustada à rotina de sessões de hemodiálise. Essa dependência é identificada e o cotidiano, modificado. Por conseguinte, eles passam a viajar menos e para locais mais próximos, buscar informações acerca da sua doença e tratamento, reconhecem suas limitações e seguem "Percebendo o cotidiano modificado", como demonstrado nos trechos seguintes:

Não podemos fazer esforço por causa da fístula, não podemos comer sal e nem beber água. Imagina esse calor todo sem poder beber nada. Rubi

A gente não pode comer de tudo e temos que tomar cuidado com tudo que bebemos, e não conseguimos trabalhar porque temos que ir até a clínica dialisar três vezes por semana e ninguém libera pra isso. Safira

Cabe ressaltar que a percepção da condição a qual se encontra interfere no modo de acomodação às exigências impostas pela dependência por ele vivenciada. É através desta percepção que o indivíduo adota mecanismos de adaptação e, assim, promove os ajustes cotidianos necessários à construção do processo de enfrentamento diante do contexto vivido.

\section{CONSIDERAÇÕES DO ESTUDO}

Valores, princípios e crenças interferem na eleição dos mecanismos utilizados para enfrentar a situação, e o modo como cada indivíduo vivencia o processo de uma mesma circunstância estressora é singular e depende, entre outros fatores, de concepções que ele próprio detinha acerca do contexto vivenciado antes de estar inserido em uma nova situação.

Assim, fica evidenciado que o apoio social, a educação e orientações que promovam o bem-estar são intervenções que devem fazer parte do planejamento da assistência ofertada pelos enfermeiros a esta clientela, adotando assim um enfoque mais abrangente ao cuidado, antes de tudo dotado de complexidades, singularidades e especificidades.

0 apoio de pessoas queridas pelo indivíduo o ajuda a enfrentar situações estressoras, portanto, o estímulo para que a interação cliente-enfermeiro seja saudável e amistosa deve ser encorajado a fim de que haja uma relação de ajuda entre os indivíduos, onde quem precisa de apoio fica menos tenso e quem oferece se sente necessário e importante.

Neste contexto, o enfermeiro deve somar esforços na tentativa não só de inserir na conjuntura da assistência os indivíduos diretamente afetados, mas também estimular que suas famílias, grupos sociais e outros profissionais façam parte de um ambiente onde haja espaço para descobertas pessoais e 
aprendizado, além de manutenção e desenvolvimento social e espiritual.

Outro fator importante a ser considerado pelo enfermeiro é a educação, pois fornece ao indivíduo a capacidade de lidar com adversidades eventuais. Assim, o enfermeiro, como educador, deve estimular a prática de atividades educativas, oferecendo a estes indivíduos a oportunidade de conhecer mais sobre sua doença, tratamento e possibilidades que 0 auxiliem na adoção de mecanismos para enfrentar a situação vivenciada.

A educação do cliente ainda pode auxiliar o enfermeiro como mediadora em situações em que haja falha na adesão ao tratamento ou dificuldade no entendimento de questões terapêuticas ou sociais advindas do cotidiano, uma vez que, através da ampliação de questões acerca do contexto vivido e do apoio social, pode haver conscientização do indivíduo para a adoção das orientações recebidas. Logo, no papel do enfermeiro como educador, o conhecimento associado às ações educativas ajuda na retomada do controle sobre a vida alterada, pelo cotidiano imposto pela doença crônica e pela perda da autonomia associada.

A atividade educativa do enfermeiro deve ainda se ampliar para além das orientações sobre a doença, contraindicações terapêuticas e dietéticas e, não obstante tudo isso, seguir para

\section{REFERÊNCIAS}

1.Valadares GV. A formação profissional e o enfrentamento do novo: a experiência do enfermeiro em setores especializados. [tese de doutorado] Rio de Janeiro (RJ): Escola de Enfermagem Anna Nery/ UFRJ; 2006.

2.Capra F. 0 Ponto de mutação. São Paulo (SP): Cultrix; 1986.

3.Martins CA, Almeida AAM, Souza Maet al. Casas de Parto: sua Impor tância na Humanização da Assistência ao Parto e Nascimento. Rev Eletr Enferm [on-line] 2005 set [citado 10 abr 2007]; 7 (3): [aprox. 8 telas]. Disponível em http://www.fen.ufg.br/revista/ revista7_3/v7n3.htm

4.Organização Mundial de Saúde (OMS). WHOQOL-BREF Introduction, Administration, Scoring and Generic Version of the Assessment.[on-line] [citado 24 maio 2008]. Disponível em: http:// www.ufrgs.br/psiq/whogol-100.html.

5.Organização Mundial de Saúde (OMS). Basic Documents. Supplement 2006. Genebra: 2006. [on - line] [citado 24 maio 2008] Disponível em: http://www.who.int/governance/eb/constitution/en/index.html.

6.Gualda DMR, Bergamasco RB, organizadoras. Enfermagem, cultura e o processo saúde-doença. São Paulo (SP): Ícone; 2004.

7.Pacheco GS, Santos I, Bregman R. Clientes com doença renal crônica: avaliação de enfermagem sobre a competência para o autocuidado. Esc Anna Nery Rev Enferm 2007 mar; 11(1): 44-51.

8.Bringuente MEO. Estressores vivenciados por paciente de terapia intensiva e suas estratégias de enfrentamento: um estudo direcionado à assistência de enfermagem. [tese de doutorado] Rio de Janeiro (RJ): Escola de Enfermagem Anna Nery/UFRJ; 2000.

9.Freitas MC, Mendes MMR. Construindo a análise do conceito: condição crônica de saúde. In: Gualda DMR, Bergamasco RB. Enfermagem, cultura e o processo saúde-doença. São Paulo (SP): Ícone; 2004.

10.Strauss A, Glauser BG. Chronic illnes and the quality oh life. Saint Louis (MO): Mosby; 1984. o campo social e psicológico, onde estratégias para a melhoria da qualidade de vida destes indivíduos devem ser consideradas, orientadas e estimuladas.

Sendo assim, juntamente com o estilo de vida e o apoio social, cultivar uma atitude positiva é um excelente modo de contribuir para o bem-estar e a qualidade de vida, auxiliando o indivíduo a lidar de maneira saudável com uma situação estressora. A prática de exercícios físicos regulares, sob orientação médica e supervisão de educador físico, devidamente capacitado, auxilia a diminuição do estresse provocado pelo cotidiano da doença crônica, favorecendo o enfrentamento de situações estressoras.

Desta forma, os dados apreendidos indicam que o cuidado de enfermagem aos clientes dependentes de hemodiálise deve transcender o tratamento tradicional, atendendo as especificidades do cliente como um todo, contribuindo, assim, para melhorias na qualidade de vida destes indivíduos.

Fica evidenciado, portanto, que a assistência a estes clientes de forma sistêmica constitui um desafio aos enfermeiros que devem garantir a qualidade do cuidado ofertado, possibilitando que a clientela em questão tenha suas especificidades atendidas e tornando possível a compreensão da sua situação de saúde e reforço no estímulo de estratégias de enfrentamento.

11.Trentini M, Silva DGV, Leiman AH. Mudanças no estilo de vida enfrentadas por pacientes em condições crônicas de saúde. Rev Gaucha Enferm 1990 jan/mar; 11 (1): 18-28.

12.Barros E, organizador. Nefrologia: rotinas, diagnósticos e tratamento. Porto Alegre (RS): Artmed; 1999.

13.Organização Mundial de Saúde (OMS). Instrumentos de medida de qualidade de vida/ desenvolvimento do WHOQOL-100. [on-line] [citado 24 mai 2008] Disponível em: http://www.ufrgs.br/psiq/whoqol100.html.

14.Cianciarullo TI, Fugulin FMT, Andreoni S. A hemodiálise em questão: opção pela qualidade assistencial. São Paulo (SP): Ícone; 1998.

15.Souza LJE, Barroso MGT. Qualidade de vida na criança acidentada. Texto\& Contexto Enferm 1999 set/dez; 8 (3): 308-17.

16. Martins MRI, Cesarino CB. Qualidade de vida de pessoas com doença renal crônica em tratamento hemodialítico. Rev Latino-am Enfermagem 2005 set/out; 13 (5): 670-76.

17.Strauss A, Corbin J. Basics of qualitative research: grounded theory procedures and techniques. (CA), Sage Publications: 1991.

18.Santos S, Nóbrega MML. A Grounded Theory como alternativa metodológica para a pesquisa em enfermagem. Rev Bras Enferm 2002 set-out; 55 (5): 575-79.

19. Ministério da Saúde (BR). Conselho Nacional de Saúde. Resolução $n^{\circ} 196$, de 10 de outubro de 1996. Diretrizes e normas regulamentadoras de pesquisas envolvendo seres humanos. Inf Epidemiol SUS 1996; 5 (2 supl 3): 13-41. 